\title{
Electrophysiological Properties of Inhibitory Junction Potential in Murine Lower Oesophageal Sphincter
}

\author{
Kenro IMAEDA ${ }^{1}$ and Thomas C. CUNNANE ${ }^{2}$ \\ ${ }^{1}$ Department of Internal Medicine and Bioregulation, Nagoya City University Graduate \\ School of Medical Sciences, Nagoya 467-8601, Japan \\ ${ }^{2}$ Department of Pharmacology, University of Oxford, Mansfield Road, Oxford OX1 3QT, \\ $U K$
}

\begin{abstract}
The electrophysiological properties of smooth muscle in the murine lower oesophageal sphincter (LOS) were investigated by intracellular microelectrode recording. Inhibitory junction potentials (IJPs) evoked by trains of field stimulation (30 $\mathrm{V}, 0.2-0.3 \mathrm{~ms}, 10$ stimuli at $1-50 \mathrm{~Hz}$ ) were observed in the murine LOS in the presence of atropine $(1 \mu \mathrm{M})$ and nifedipine $(1 \mu \mathrm{M})$. The IJP consists of two components, which we termed fast IJP and slow IJP. The fast IJP was partly sensitive to guanethidine ( $5 \mu \mathrm{M})$, pyridoxalphosphate-6-azophenyl-2',4'-disulphonic acid (PPADS, $30 \mu \mathrm{M})$ and apamin $(0.1$ $\mu \mathrm{M})$, suggesting that the fast IJP was produced partly through the activation of apaminsensitive $\mathrm{Ca}^{2+}$-activated $\mathrm{K}^{+}$channels and of $\mathrm{P}_{2}$-purinoceptors. The other part of the fast IJP was sensitive to $\mathrm{N}^{\omega}$-nitro-L-arginine (L-NNA, $100 \mu \mathrm{M}$ ) and $1 \mathrm{H}-[1,2,4]$ oxadiazolo[4,3a]quinoxaline-1-one (ODQ, $1 \mu \mathrm{M})$, but insensitive to apamin $(0.1 \mu \mathrm{M})$, iberiotoxin (50 $\mathrm{nM})$ and charybdotoxin $(30 \mathrm{nM})$. Slow IJP was sensitive to L-NNA $(100 \mu \mathrm{M})$, ODQ (10 $\mu \mathrm{M})$ and glibenclamide $(10 \mu \mathrm{M})$, but insensitive to apamin $(0.1 \mu \mathrm{M})$, iberiotoxin (50 nM) and charybdotoxin $(30 \mathrm{nM})$. KT5823, a protein kinase $\mathrm{G}(\mathrm{PKG})$ inhibitor, had no effect on the fast and slow IJP in this tissue. It was suggested that, in the mouse LOS, adenosine trisphosphate (ATP) partly mediated the fast IJP through apamin-sensitive $\mathrm{Ca}^{2+}$-activated $\mathrm{K}^{+}$channels, and nitric oxide mediated the remained part of the fast IJP and the slow IJP through cGMP, but not PKG. ATP-sensitive $\mathrm{K}^{+}$channels were suggested to be partly involved in the production of slow IJP, but the responsible channel(s) for the nitrergic fast IJP remained unclarified.
\end{abstract}

Key words: mouse, lower oesophageal sphincter, smooth muscle, inhibitory junction potential, hyperpolarisation, apamin, ATP, nitric oxide

\section{Introduction}

It is physiologically important to keep high tone in the lower oesophageal sphincter (LOS) so as to prevent gastro-oesophageal reflux. Additionally, a transient relaxation of LOS allows the

Correspondence to: K. Imaeda, Department of Internal Medicine and Bioregulation, Nagoya City

University, Graduate School of Medical Sciences, Nagoya 467-8601, Japan

Phone: +81-52-853-8211 Fax: +81-52-852-0952 e-mail: kimaeda@med.nagoya-cu.ac.jp 
passage of food and liquid into the stomach (Goyal and Paterson, 1989). The inhibitory neural regulation in LOS has been well investigated, and nonadrenergic noncholinergic (NANC) nerves have been reported as playing an important role in causing of relaxation in this region (Hoyle and Burnstock, 1989). Inhibitory junction potential (IJP) evoked by stimulation of enteric autonomic nerves causes not all but a part of the relaxation evoked by stimulation of enteric autonomic nerves (Bolton and Large, 1986; Imaeda et al., 1998). So IJP could be an important phenomenon for investigating the electrophysiological properties of inhibitory neural transmission. Clarification of the underlying mechanisms of the generation of IJP leads to the identification not only of the transmitter(s) but also of the channel(s) involved in these hyperpolarising responses. IJP in LOS are observed in several experimental animals, for example dog (Allescher et al., 1988), opossum (Daniel et al., 1989; Conklin et al., 1993), guineapig (Imaeda et al., 1998; Yuan et al., 1998) and mouse (Ward et al., 1998). In the guinea-pig LOS, nitric oxide (NO) and adenosine triphospahte (ATP) have been proposed as inhibitory neurotransmitters and small conductance $\mathrm{Ca}^{2+}$-activated $\mathrm{K}^{+}\left(\mathrm{SK}_{\mathrm{Ca}}\right)$ channels played an important role in eliciting IJP (Imaeda et al., 1998). In the murine LOS, $\mathrm{N}^{\omega}$-nitro-L-arginine methyl ester (LNAME), a nitric oxide synthase (NOS) inhibitor, inhibited both rapid and slow phase of IJP (Ward et al., 1998). In addition, in genetically neuronal NOS locking mice, LOS failed to produce electrical field stimulation (EFS) -induced relaxation (Kim et al., 1999). These observations suggest that NO mediates inhibitory neurotransmission in the murine LOS.

In the present study, we have investigated the electrophysiological properties of IJP in murine LOS circular smooth muscle by using intracellular membrane potential recording technique, in order to elucidate the transmitter(s) and the channel(s) involved.

\section{Methods}

\section{Tissue Preparation}

Male BALB/C mice, between the ages of 8 and 12 weeks postpartum, killed by cervical dislocation, which was approved by the Animal Ethics Committees of the University of Oxford. The stomach, including a portion of oesophagus, was quickly excised and placed in Krebs solution at room temperature. The oesophagus and stomach was cut open in the longitudinal direction along the greater curvature, and was pinned flat with the mucosal side up. The mucosa of stomach and oesophagus was removed with micro-scissors. Transverse strips (1-1.5 $\mathrm{mm}$ wide and 5-7 mm long) were cut from the area of the LOS along circular muscle, which revealed the thickened region at the junction between oesophagus and stomach (Ward et al., 1998).

\section{Intracellular recording}

Preparations were immobilized by pinning them with the mucosal side up to the Sylgard covered base of a $3 \mathrm{ml}$ Perspex organ bath, superfused at a rate of $3 \mathrm{ml} \mathrm{min}^{-1}$ with warmed $\left(37^{\circ} \mathrm{C}\right) \mathrm{Krebs}$ solution bubbled with $95 \% \mathrm{O}_{2}-5 \% \mathrm{CO}_{2}$ to $\mathrm{pH}$ 7.4. The ionic composition of Krebs solution was (mM): $\mathrm{NaCl}, 118.4 ; \mathrm{NaHCO}_{3}, 25.0 ; \mathrm{NaH}_{2} \mathrm{PO}_{4}, 1.13 ; \mathrm{CaCl}_{2}, 1.8 ; \mathrm{KCl}, 4.7 ; \mathrm{MgCl}_{2}, 1.3$; glucose, 11.1. Conventional intracellular recording techniques were used to measure the 
changes in membrane potential of circular smooth muscle cells of the mouse LOS. Changes in membrane potential were recorded by using glass micro-electrodes (outer diameter $1.5 \mathrm{~mm}$, filled with $1 \mathrm{M} \mathrm{KCl}$, resistances 80-150 M $\Omega$ ) connected to the high input impedance headstage of an Axoclamp-2A (Axon Instruments) and displayed on a cathode-ray oscilloscope (2430A, Tektronix). After low-pass filtering (cut off frequency, $10 \mathrm{~Hz}$ ), potential changes were digitized and stored on a Macintosh computer (MacLab, Chart Version 3.3.3, ADI Instruments) for subsequent analysis. The criteria for the acceptable impalement of a smooth muscle cell were abrupt sharp changes in potentials upon both impalement and withdrawal, and a stable recording for at least $3 \mathrm{~min}$ prior to each experimental procedure. Intrinsic nerves were activated by field stimulation using a pair of platinum electrodes arranged in parallel about $3 \mathrm{~mm}$ apart. A pair of stimulating electrodes was located to just touch on the tissue. Rectangular voltage pulses (pulse width, $0.2-0.3 \mathrm{~ms}$; intensity, $30 \mathrm{~V}$ ) were delivered from a digital stimulator coupled to an optically isolated stimulus unit (Applegarth Instruments, Oxford, UK). The neural selectivity of stimulating pulses was confirmed as evoked responses were abolished by $0.3 \mu \mathrm{M}$ tetrodotoxin.

\section{Chemicals}

Drugs used were 4-aminopyridine (4-AP), atropine sulphate, apamin, charybdotoxin, glibenclamide, guanethidine, iberiotoxin, KT-5823, $\mathrm{N}^{\omega}$-nitro-L-arginine (L-NNA), nifedipine, $1 \mathrm{H}-$ [1,2,4] oxadiazolo[4,3-a]quinoxalin-1-one (ODQ), pyridoxalphosphate-6-azophenyl-2',4'disulphonic acid (PPADS), sodium nitroprusside (SNP), suramin, tetraethylammonium chloride (TEA chloride), tetrodotoxin (TTX), (all from Sigma). The drugs were dissolved in distilled water or dimethyl sulfoxide (DMSO; Sigma) at concentrations at least 1000 times higher than used in the experiments, and diluted in Krebs solution to obtain the required concentrations.

\section{Statistical Analysis}

Measured values were expressed as means \pm S.E.M. The $\mathrm{n}$ value refers to the number of preparations. Statistical significance of the values was determined using paired or unpaired Student's $t$ test. Probabilities of less than $5 \%(P<0.05)$ were considered significant.

\section{Results}

\section{Resting membrane potentials and excitatory junction potential}

At rest, it was noted that the membrane potential underwent spontaneous fluctuations (amplitude $2.9 \pm 0.2 \mathrm{mV}$; frequency $1.2 \pm 0.04 \mathrm{~Hz}, \mathrm{n}=22$ ). The spontaneous fluctuations were insensitive to nifedipine ( $1 \mu \mathrm{M}$; amplitude $2.8 \pm 0.3 \mathrm{mV}$; frequency $1.3 \pm 0.06 \mathrm{~Hz}, \mathrm{n}=13)$. The control resting membrane potential ranged between -38 and $-56 \mathrm{mV}$ and was not significantly altered by $1 \mu \mathrm{M}$ nifedipine (control, $-45.0 \pm 0.7 \mathrm{mV}, \mathrm{n}=27$; nifedipine, $-45.3 \pm 0.8 \mathrm{mV}, \mathrm{n}=22$ ) and $1 \mu \mathrm{M}$ atropine (control, $-45.1 \pm 0.9 \mathrm{mV}, \mathrm{n}=21$; atropine, $45.6 \pm 0.9 \mathrm{mV}, \mathrm{n}=27$ ). In the absence of atropine, low frequency of electrical field stimulation (EFS, $1 \mathrm{~Hz}$ ) evoked transient depolarising responses with an amplitude of $9.3 \pm 1.5 \mathrm{mV}(\mathrm{n}=3)$ and a duration of $0.52 \pm 0.003 \mathrm{~s}(\mathrm{n}=3)$. These depolarising responses were abolished by TTX $(0.3 \mu \mathrm{M}, \mathrm{n}=3)$ or atropine $(1 \mu \mathrm{M}, \mathrm{n}=3)$, indicating 
that EFS may release acetylcholine (ACh) from excitatory nerves and results in evoking excitatory junction potentials (EJPs). Therefore, the following intracellular membrane potential recordings were carried out in the presence of both nifedipine and atropine to prevent contraction and to ensure stable recording.

\section{Frequency-dependency of IJP in murine LOS}

The application of EFS (duration, $0.2-0.3 \mathrm{~ms}$; intensity, $30 \mathrm{~V}$; 10 pulses; frequency 1-50 Hz) in the presence of nifedipine $(1 \mu \mathrm{M})$ and atropine $(1 \mu \mathrm{M})$ evoked transient hyperpolarising responses in smooth muscle cells. At a low frequency $(1 \mathrm{~Hz})$, EFS evoked only a fast transient hyperpolarisation, but at higher frequencies (between 5 and $50 \mathrm{~Hz}$ ), the hyperpolarisation evoked by EFS consisted of two components. It was a fast component which was a rapid and transient hyperpolarisation starting just after the application of EFS (duration, $2.2 \pm 0.1 \mathrm{~s}$ at 20 $\mathrm{Hz}, \mathrm{n}=11$ ), followed by a slow component which started at the point that repolarising phase changed abruptly and ended when the membrane potential recovered to the resting level (duration, $30.9 \pm 4.3 \mathrm{~s}$ at $20 \mathrm{~Hz}, \mathrm{n}=11$ ). These hyperpolarising responses were abolished by the application of TTX $(0.3 \mu \mathrm{M})$, indicating that they resulted from nerve stimulation, and could be called an inhibitory junction potential (IJP). We also termed a fast component of IJP "fast IJP" and a slow component of IJP "slow IJP". The amplitudes of both fast and slow IJPs were increased in the frequency dependent manner between 1 and $50 \mathrm{~Hz}$ (Fig. 1). The effects of drugs were observed on IJPs of maximal amplitude. To obtain the maximal amplitude of IJPs, we applied EFS of 20 or $50 \mathrm{~Hz}$ in the following experiments.

\section{Neurotransmitters of IJP}

L-NNA (100 $\mu \mathrm{M})$, an inhibitor of NOS, significantly reduced the amplitude of the fast IJP and completely abolished the slow IJP (Fig. 2). It is well known that NO activates guanylate cyclase, resulting in increasing the level of cGMP (Moncada et al., 1991). So, we investigated the effect of ODQ, an inhibitor of guanylate cyclase (Garthwaite et al., 1995). ODQ $(1 \mu \mathrm{M})$ significantly reduced the amplitude of the fast IJP and completely abolished the slow IJP (Fig. 3). To test whether NO is likely to produce a hyperpolaisation in this tissue, SNP, a NO donor, was applied cumulatively. SNP produced a concentration-dependent hyperpolarisation between $10 \mathrm{nM}$ and $100 \mu \mathrm{M}$. To investigate whether cGMP is involved in the SNP-induced hypeprolarisation, ODQ was applied. As higher concentration of ODQ was needed to inhibite NO donor induced hyperpolarisation in the different tissue (Goyal and He, 1998), $10 \mu \mathrm{M}$ ODQ was used. The hyperpolarisation induced by SNP $(100 \mu \mathrm{M})$ was abolished by ODQ $(10 \mu \mathrm{M})$ (Fig. 4). Furthermore, the involvement of protein kinase G (PKG) was investigated by using KT 5823, an inhibitor of PKG (Kase et al., 1987; Cornfield et al., 1996). However, KT $5823(1 \mu \mathrm{M})$ inhibited neither fast nor slow components of the IJP $(\mathrm{n}=3)$.

Further responsible transmitter(s) for the fast IJP was investigated. Guanethidine $(5 \mu \mathrm{M})$ partially reduced the amplitude of the fast IJP (control, $19.5 \pm 1.0 \mathrm{mV}, \mathrm{n}=4$; guanethidine, $13.8 \pm$ $0.3 \mathrm{mV}, \mathrm{n}=4, P<0.05)$ (Fig. 5). PPADS $(30 \mu \mathrm{M})$, an inhibitor of $\mathrm{P}_{2}$ purinoceptor (Lambrecht $e$ al., 1992), also inhibited the fast IJP (control, $22.3 \pm 1.8 \mathrm{mV}, \mathrm{n}=4$; PPADS, $16.6 \pm 1.4 \mathrm{mV}, \mathrm{n}=4$, $P<0.05)$ (Fig. 6). 

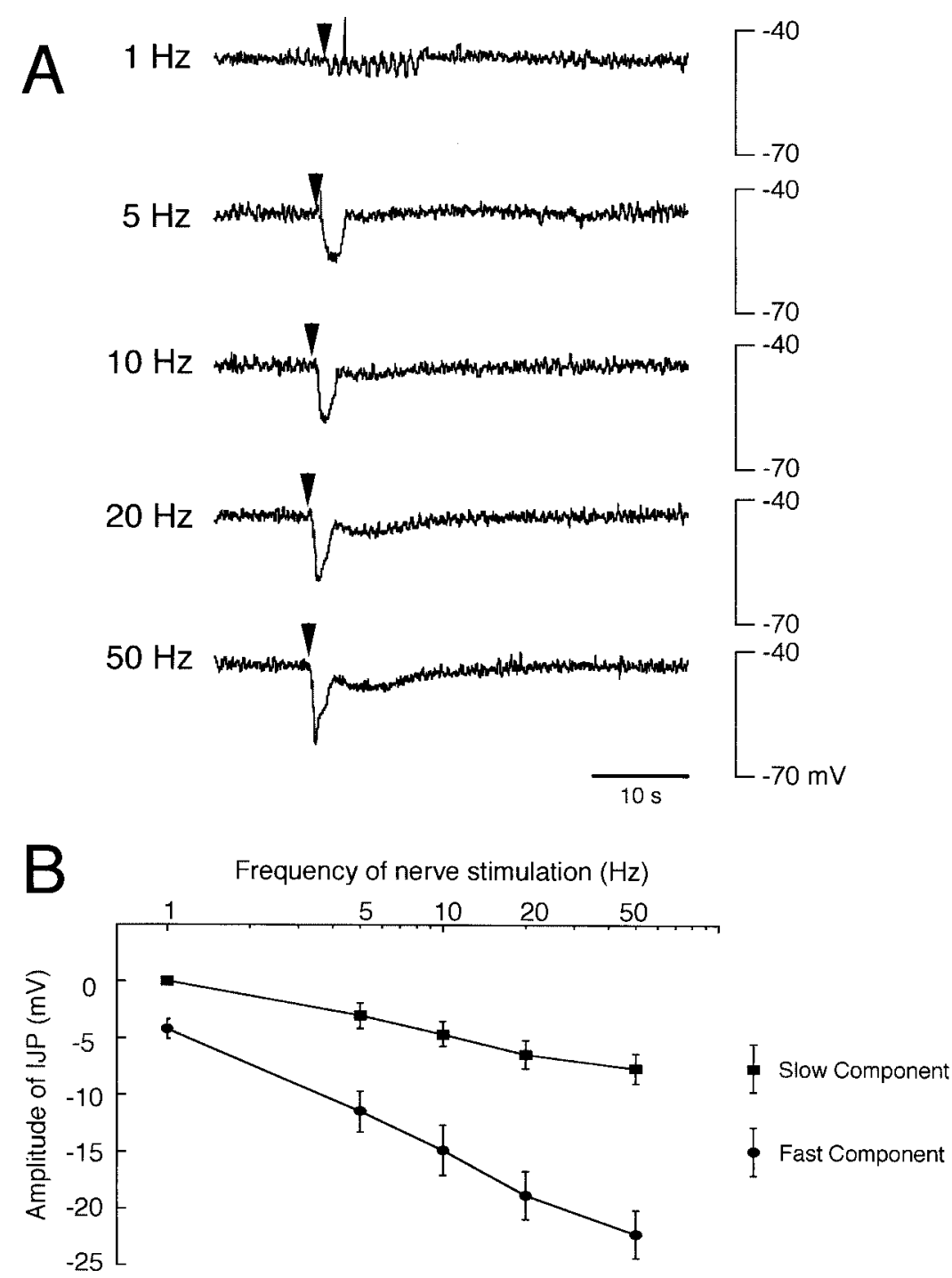

Fig. 1. Frequency-dependency of IJP in circular smooth muscle of the murine LOS. A: Representative traces of IJPs evoked by EFS in the presence of atropine $(1 \mu \mathrm{M})$ and nifedipine $(1 \mu \mathrm{M})$. The resting membrane potential of smooth muscle cell was -42 $\mathrm{mV}$. EFS was applied at the time indicated by an arrow head. B: Relationship between frequency of EFS and amplitude of IJP. Closed circle demonstrates the amplitude of the fast IJP and closed square demonstrates the amplitude of the slow IJP. Values are means \pm S.E.M. $(n=5)$.

\section{Effect of $K^{+}$-channel inhibitors on IJP}

The responsible channels for both fast and slow IJPs were investigated. Glibenclamide, an inhibitor of ATP-sensitive $\mathrm{K}^{+}\left(\mathrm{K}_{\mathrm{ATP}}\right)$ channel depolarised the membrane of smooth muscle cells from $-45.4 \pm 2.2 \mathrm{mV}$ to $-40.8 \pm 2.3 \mathrm{mV}(\mathrm{n}=5, P<0.05)$, and greatly reduced the amplitude of the slow IJP (Fig. 7). Apamin, an inhibitor of $\mathrm{SK}_{\mathrm{Ca}}$ channel also depolarised the membrane from 
A
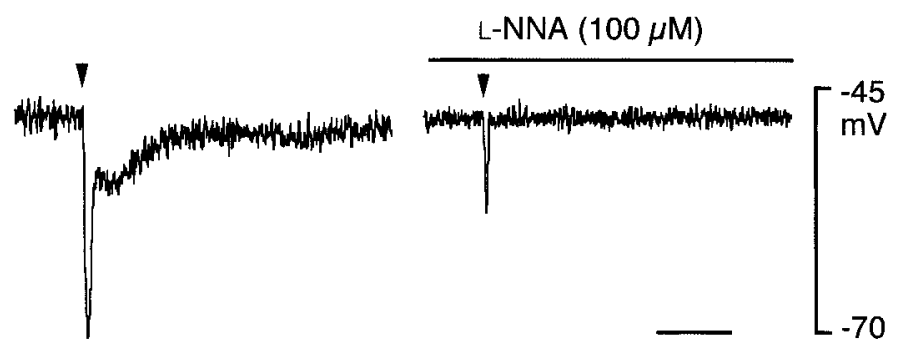

$10 \mathrm{~S}$

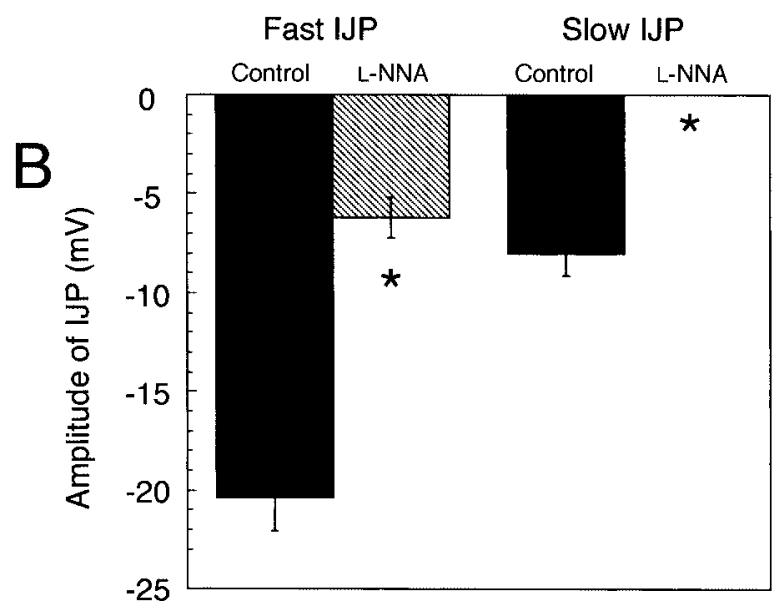

Fig. 2. Effects of L-NNA on IJP. A: Representative traces showing the effect of L-NNA (100 $\mu \mathrm{M})$ on IJP. IJP was evoked by EFS (10 pulses in $20 \mathrm{~Hz}, 30 \mathrm{~V}$ intensity) in the presence of atropine $(1 \mu \mathrm{M})$ and nifedipine $(1 \mu \mathrm{M})$. The resting membrane potential was $-47 \mathrm{mV}$. EFS was applied at the time indicated by an arrow head. B: Each column indicates amplitude of the fast and slow IJP in the absence and presence of $\mathrm{L}$ NNA $(100 \mu \mathrm{M})$. Values are mean \pm S.E.M. $(\mathrm{n}=5) .{ }^{\star} P<0.05$ vs. control.

$-43.8 \pm 0.7 \mathrm{mV}$ to $-40.6 \pm 0.8 \mathrm{mV}(\mathrm{n}=5, P<0.05)$, and partially reduced the amplitude of the fast IJP (Fig. 8).

To investigate an apamin-insensitive component of the fast IJP, inhibitors of large conductance $\mathrm{Ca}^{2+}$-activated $\mathrm{K}^{+}\left(\mathrm{BK}_{\mathrm{Ca}}\right)$ channels were applied. However, neither iberiotoxin $(0.1$ $\mu \mathrm{M}, \mathrm{n}=4)$ nor charybdotoxin (30 $\mathrm{nM}, \mathrm{n}=2$ ) inhibited the apamin-insensitive component of the fast IJP. The combined application of apamin $(0.1 \mu \mathrm{M})$ and charbdotoxine $(30 \mathrm{nM})$ did not attenuate the fast IJP ( $n=2)$, either.

To investigate the properties of the apamin-insensitive component of the fast IJP, we applied apamin and ODQ cumulatively. In the presence of apamin, the slow and the residual fast IJP were observed. ODQ $(10 \mu \mathrm{M})$ abolished the slow IJP and greatly attenuated the residual fast IJP (Fig. 9). The effect of apamin $(0.1 \mu \mathrm{M})$ on hyperpolarisation evoked by SNP $(100 \mu \mathrm{M})$ was also investigated, but apamin did not attenuate the SNP-induced hyperpolarisation (SNP, $22.3 \pm$ 

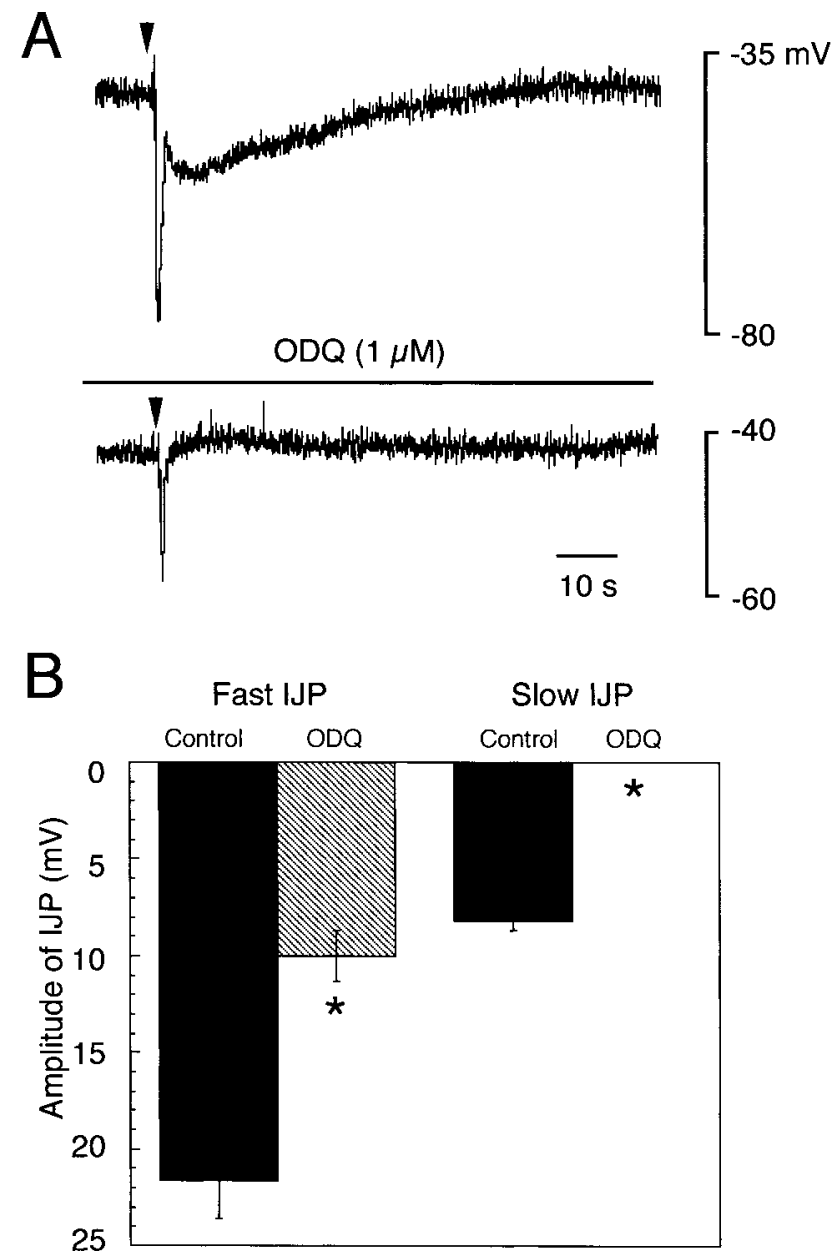

Fig. 3. Effects of ODQ on IJP. A: Representative traces showing the effects of ODQ $(1 \mu \mathrm{M})$ on IJP. IJP was evoked by EFS ( 10 pulses in $20 \mathrm{~Hz}, 30 \mathrm{~V}$ intensity) in the presence of atropine $(1 \mu \mathrm{M})$ and nifedipine $(1 \mu \mathrm{M})$. The resting membrane potential was $-38 \mathrm{mV}$. EFS was applied at the time indicated by an arrow head. B: Each column indicates amplitude of the fast and slow IJP in the absence and presence of ODQ $(1 \mu \mathrm{M})$. Values are mean \pm S.E.M. $(\mathrm{n}=5) .{ }^{\star} P<0.05$ vs. control.

$1.5 \mathrm{mV}$; SNP with apamin, $21.3 \pm 2.6 \mathrm{mV}, \mathrm{n}=3)$.

\section{Discussion}

In various species, stimulation of intrinsic enteric nerves evokes NANC IJPs in LOS (Conklin et al., 1993; Yuan et al., 1998; Ward et al., 1999). The considerable neurotransmitters involve NO, ATP, vasoactive intestinal polypeptide and pituitary adenylate cyclase-activating polypeptide, and responsible channels suggested are apamin-sensitive $\mathrm{K}^{+}$channels and apamininsensitive channels (Rae and Muir, 1996; Imaeda et al., 1998; Selemidis et al., 1998). In the 

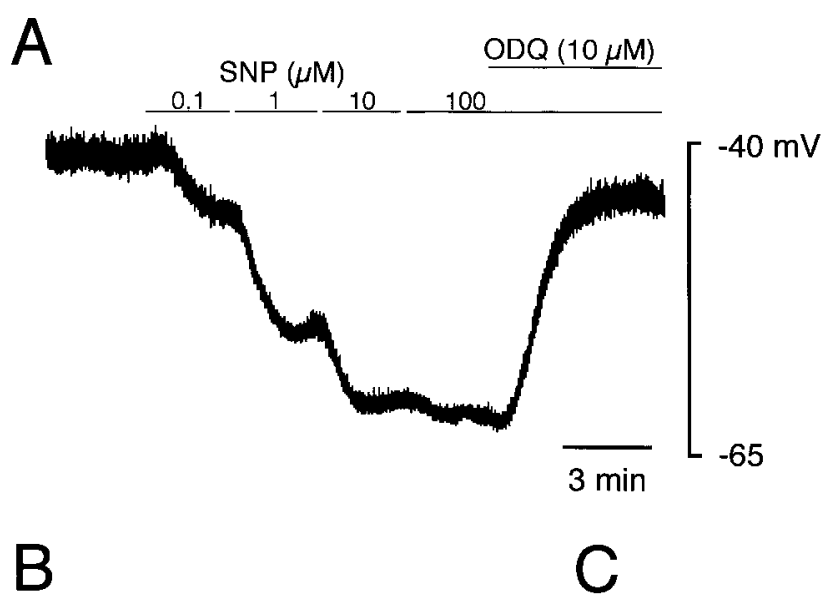

Concentration of SNP $(\mu \mathrm{M})$

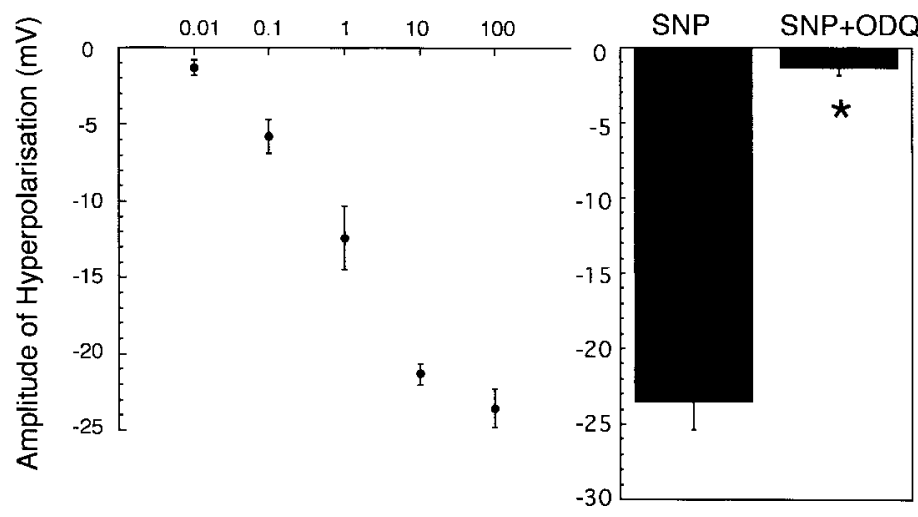

Fig. 4. Concentration-dependency of the SNP-induced hyperpolarisation and effect of ODQ on the SNP-induced hyperpolarisation. A: Representative trace of SNP-induced hyperpolarisation and the effect of ODQ on the hyperpolarisation. SNP was applied cumulatively from 0.1 to $100 \mu \mathrm{M}$. ODQ $(10 \mu \mathrm{M})$ was applied in the presence of SNP $(100 \mu \mathrm{M})$. Nifedipine $(1 \mu \mathrm{M})$ was present throughout the recording. The initial resting membrane potential was $-41 \mathrm{mV}$. B: Relationship between concentration of SNP and amplitude of SNP-induced hyperpolarisation. Values are means \pm S.E.M. $(n=4-6)$. C: Each column indicates amplitude of SNP $(100 \mu \mathrm{M})$-induced hyperpolarisation in the absence and presence of ODQ $(10 \mu \mathrm{M})$. Values are mean \pm S.E.M. $(\mathrm{n}=6) .{ }^{\star} P<0.05$ vs. SNP.

present study, cholinergic EJP in the murine LOS was observed and thus the electrophysiological properties of IJP in non-cholinergic condition were investigated. The results show that IJP evoked by EFS consists of two components, namely a fast and a slow IJP. The slow IJP was completely abolished by L-NNA, a NOS inhibitor, indicating that NO mediates the slow IJP. The fast IJP was divided into two parts. About two thirds of the fast IJP was inhibited by L-NNA, indicating that this part is also mediated by NO. About one third of the fast IJP was inhibited by PPADS, an inhibitor of $\mathrm{P}_{2}$ purinoceptor (Lambrecht et al., 1992), indicating that ATP mediates the fast IJP. There are therefore three components of IJP, a purinergic fast IJP, a nitrergic fast IJP and a nitrergic slow IJP. In the previous study about IJP in the murine 

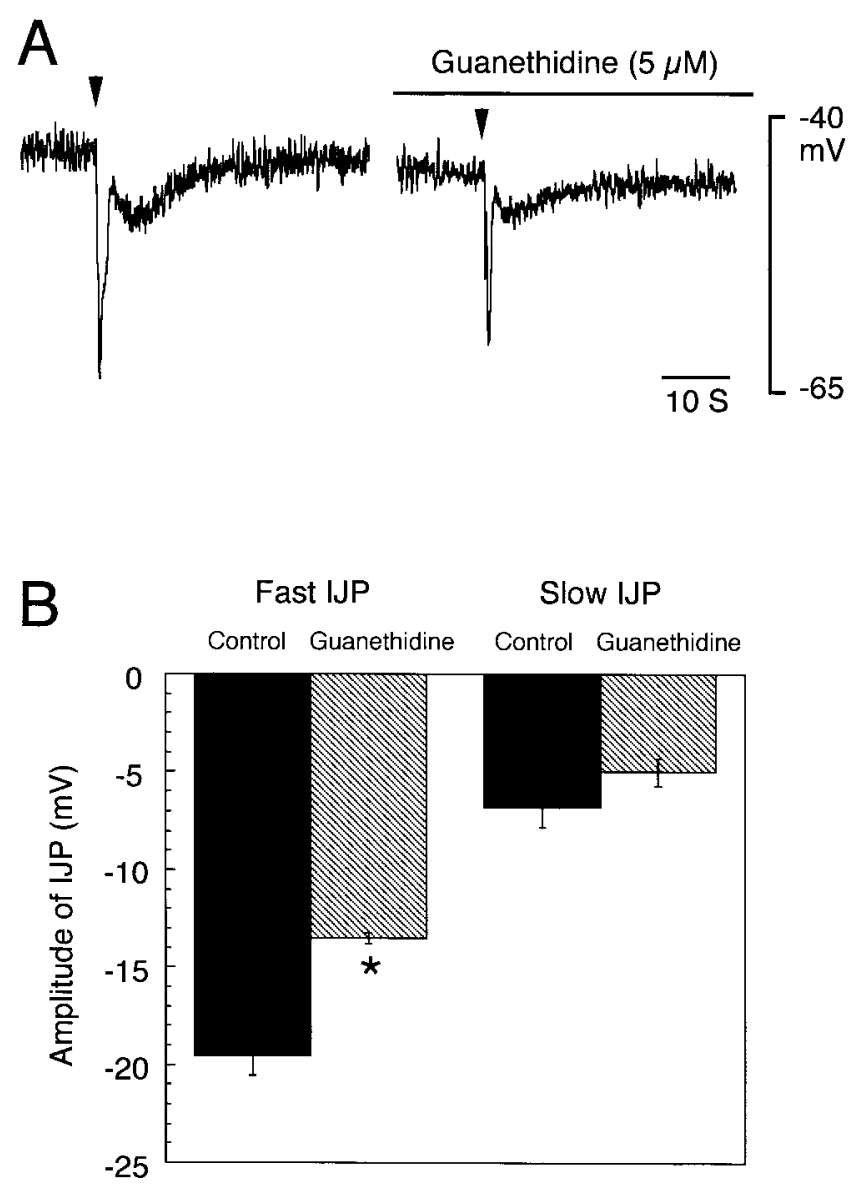

Fig. 5. Effect of guanethidine on IJP. A: Representative traces showing the effect of guanethidine $(5 \mu \mathrm{M})$ on IJP. IJP was evoked by EFS (10 pulses in $20 \mathrm{~Hz}, 30 \mathrm{~V}$ intensity) in the presence of atropine $(1 \mu \mathrm{M})$ and nifedipine $(1 \mu \mathrm{M})$. The resting membrane potential was $-43 \mathrm{mV}$. EFS was applied at the time indicated by an arrow head. B: Each column indicates amplitude of the fast and slow IJP in the absence and presence of guanethidine $(5 \mu \mathrm{M})$. Values are mean \pm S.E.M. $(\mathrm{n}=4) .{ }^{\star} P<0.05$ vs. control.

LOS has reported that both fast and slow IJP was greatly inhibited by L-NAME (Ward $e t$ al., 1998). However, the properties of the residual fast IJP and the responsible channels have not been referred. In the present study, interest focuses on firstly clarifying the transmitters involved, and second investigating the responsible mechanisms or channels for the respective components of hyperpolarisation.

\section{Nitrergic fast and slow IJPs}

Many studies have reported that NO plays an important role in inhibitory neurotransmission in the gastrointestinal tract. It is also the case in the LOS of several species. NO has been clarified as the important transmitter of IJP in opossum (Conklin et al., 1993), dog (De Man et al., 1991), cat (Ny et al., 1995) and guinea-pig (Imaeda et al., 1998, Yuan et al., 1998). So, NO is 

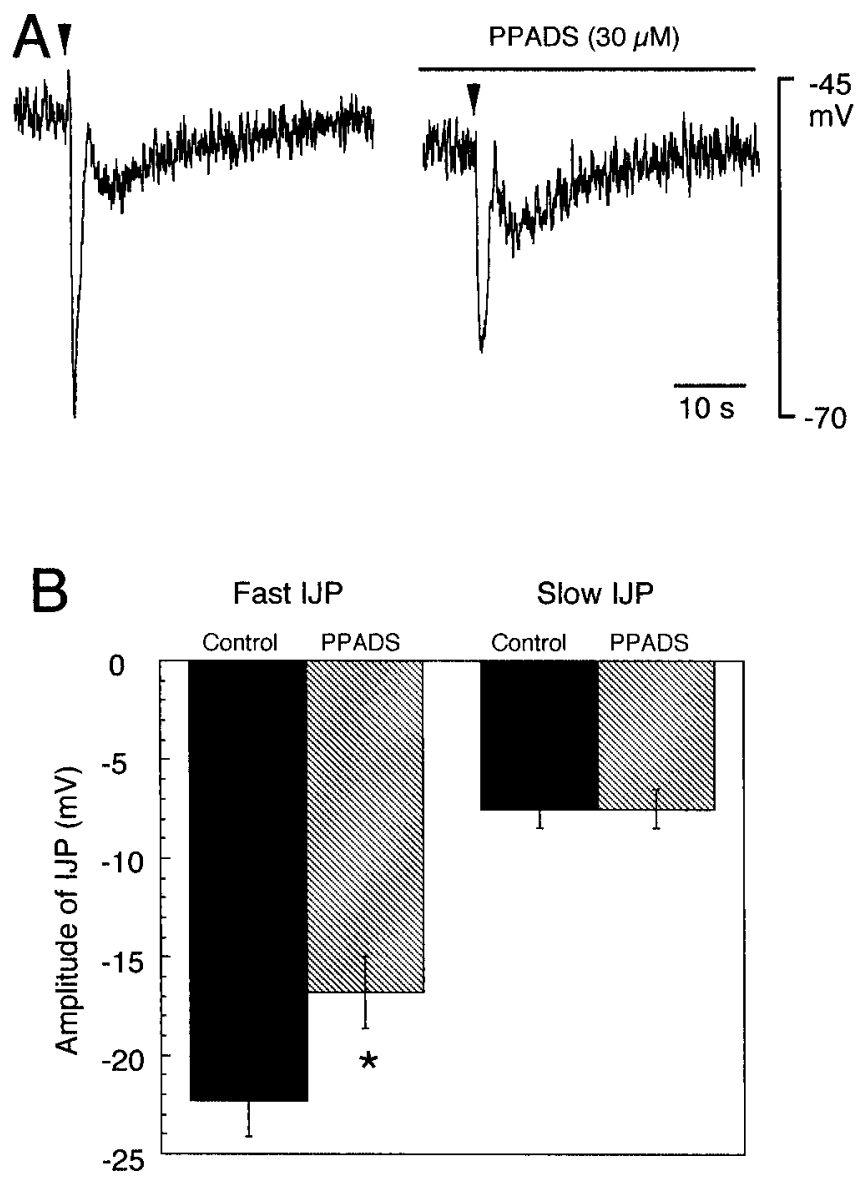

Fig. 6. Effect of PPADS on IJP. A: Representative traces showing the effect of PPADS (30 $\mu \mathrm{M})$ on IJP. IJP was evoked by EFS (10 pulses in $20 \mathrm{~Hz}, 30 \mathrm{~V}$ intensity) in the presence of atropine $(1 \mu \mathrm{M})$ and nifedipine $(1 \mu \mathrm{M})$. The resting membrane potential was $-46 \mathrm{mV}$. EFS was applied at the time indicated by an arrow head. B: Each column indicates amplitude of the fast and slow IJP in the absence and presence of PPADS $(30 \mu \mathrm{M})$. Values are mean \pm S.E.M. $(\mathrm{n}=4)$. ${ }^{\star} P<0.05$ vs. control.

a potential candidate for the neurotransmitter of IJP in the murine LOS. L-NNA is a useful tool to clarify the involvement of NO. In the present study, L-NNA inhibited the amplitude of the fast IJP greatly and abolished the slow IJP (Fig. 2). These results indicate that NO mediates both the fast and slow IJP. It is well known that NO activates guanylate cyclase, resulting in the elevation of the level of cGMP (Moncada et al., 1991). Thus, we investigated whether cGMP is involved in the production of the nitrergic IJP. The effect of ODQ, an inhibitor of guanylate cyclase (Garthwait et al., 1995), was quite similar to that of L-NNA. In detail, ODQ attenuated the amplitude of the fast IJP to about one third of the control and completely abolished the slow IJP (Fig. 3). Taken together, these results suggested that NO mediates the whole slow IJP and a part of the fast IJP through the activation of guanylate cyclase, resulting in the production of cGMP. Furthermore, the fact that SNP also causes membrane hyperpolarisation and this 

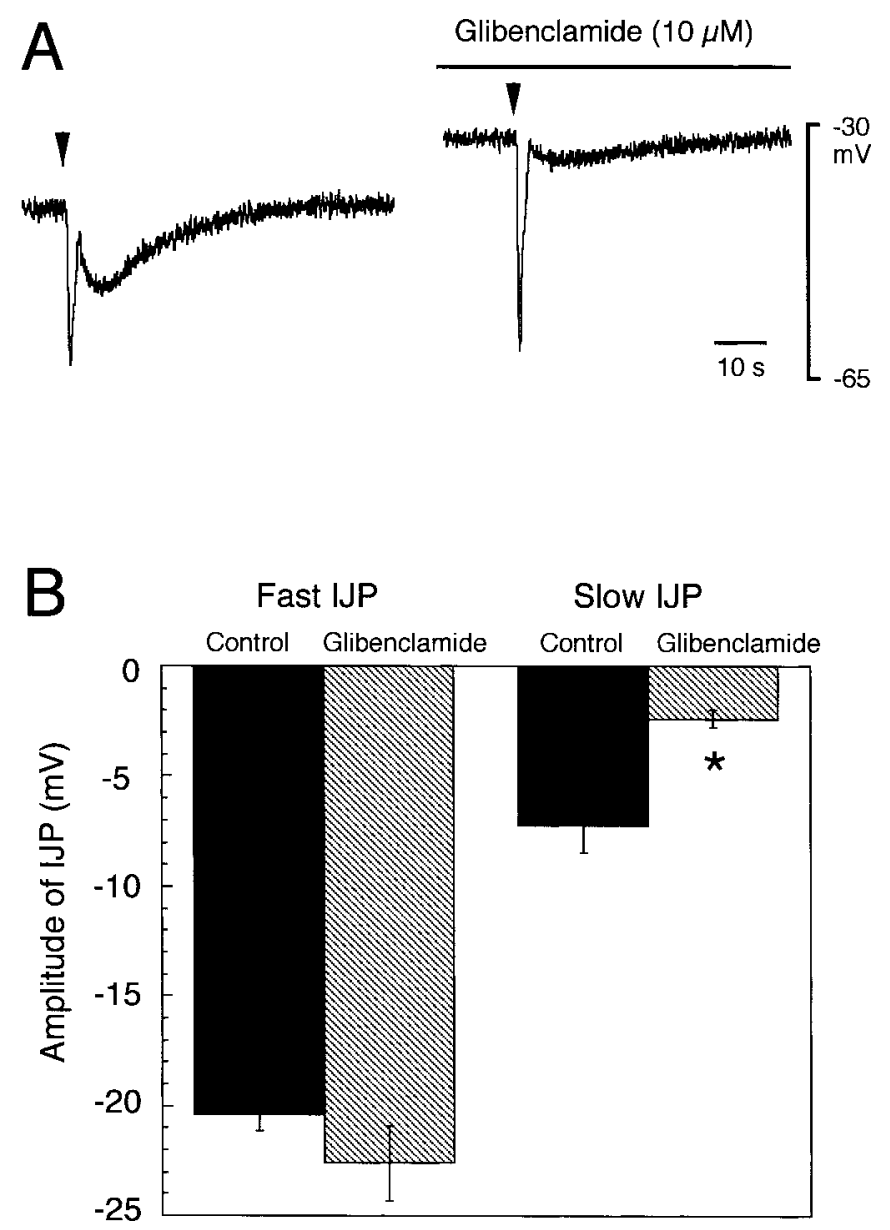

Fig. 7. Effects of glibenclamide on IJP. A: Representative traces showing the effect of glibenclamide $(10 \mu \mathrm{M})$ on IJP. IJP was evoked by EFS $(10$ pulses in $20 \mathrm{~Hz}, 30 \mathrm{~V}$ intensity) in the presence of atropine $(1 \mu \mathrm{M})$ and nifedipine $(1 \mu \mathrm{M})$. The resting membrane potential was $-39 \mathrm{mV}$. EFS was applied at the time indicated by an arrow head. B: Each column indicates amplitude of the fast and slow IJP in the absence and presence of glibenclamide $(10 \mu \mathrm{M})$. Values are mean \pm S.E.M. $(\mathrm{n}=5)$. ${ }^{\star} P<0.05$ vs. control.

hyperpolarisation is abolished by ODQ supports the involvement of cGMP in the production of the nitrergic IJP (Fig. 4).

It is still under discussion how cGMP produces membrane hyperpolarisation and what kinds of channels are activated in smooth muscle cells. Glibenclamide, an inhibitor of $\mathrm{K}_{\text {ATP }}$ channels, greatly inhibited the slow IJP (Fig. 7), suggesting that $\mathrm{K}_{\mathrm{ATP}}$ channels were involved in the slow IJP. The activation of $\mathrm{K}_{\mathrm{ATP}}$ channels by NO-cGMP pathway has been also reported in the rabbit mesenteric arterial smooth muscle cells (Murphy and Brayden, 1995). There remains the possibility that cGMP activates PKG, then PKG produces hyperpolarisation. Furthermore, in arterial smooth muscle cells, PKG directly activates $\mathrm{BK}_{\mathrm{Ca}}$ channels (Robertson et al., 1993) or activates the release of $\mathrm{Ca}^{2+}$ from intracellular store, resulting in the activation of $\mathrm{BK}_{\mathrm{Ca}}$ channels 

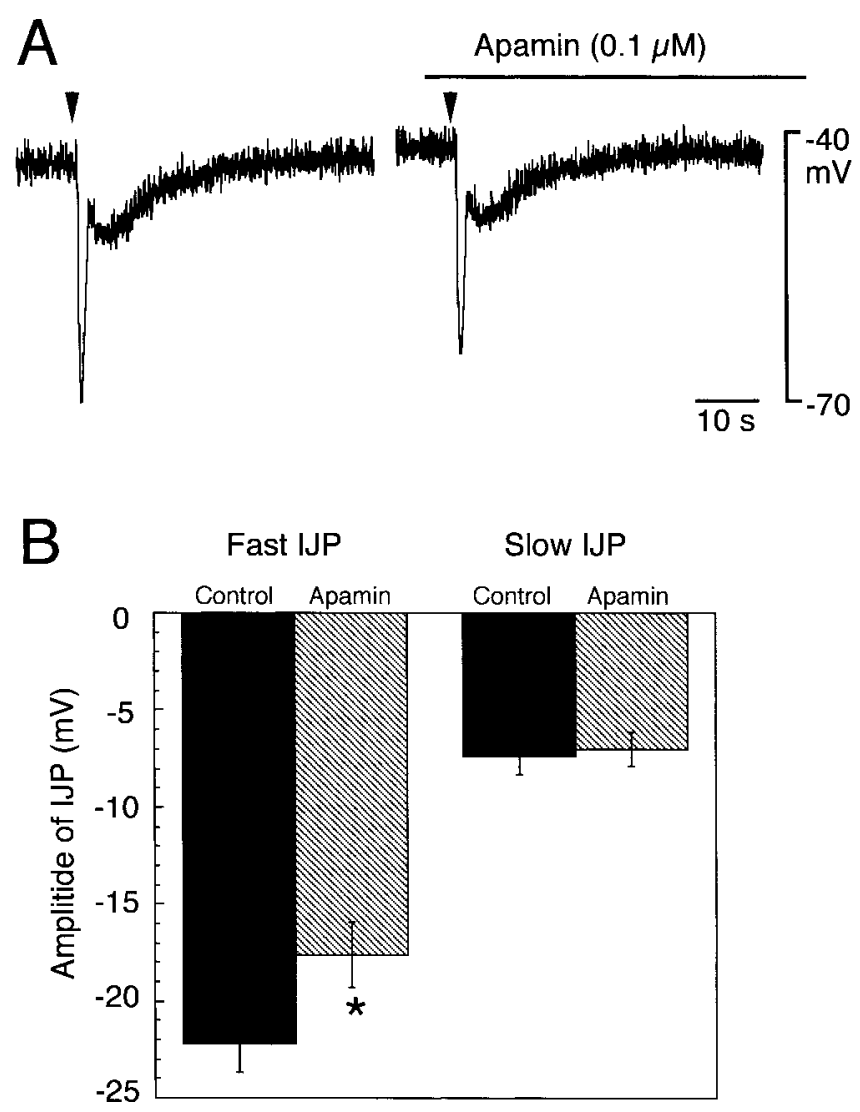

Fig. 8. Effects of apamin on IJP. A: Representative traces showing the effect of apamin $(0.1$ $\mu \mathrm{M})$ on IJP. IJP was evoked by EFS (10 pulses in $20 \mathrm{~Hz}, 30 \mathrm{~V}$ intensity) in the presence of atropine $(1 \mu \mathrm{M})$ and nifedipine $(1 \mu \mathrm{M})$. The resting membrane potential was $-43 \mathrm{mV}$. EFS was applied at the time indicated by an arrow head. B: Each column indicates amplitude of the fast and slow IJP in the absence and presence of apamin $(0.1 \mu \mathrm{M})$. Values are mean \pm S.E.M. $(\mathrm{n}=5) .{ }^{\star} P<0.05$ vs. control.

(Porter et al., 1998). However, KT 5823, an inhibitor of PKG, attenuated neither the fast nor the slow IJP. This result indicates that PKG is not involved in the production of IJP in the murine LOS. We also investigated the effect of selective inhibitors of $\mathrm{BK}_{\mathrm{Ca}}$ channels, iberiotoxin and charybdotoxin on IJP. Neither iberiotoxine nor charybdotoxin attenuated the fast IJP, suggesting that $\mathrm{BK}_{\mathrm{Ca}}$ channels are not involved in the nitregic fast IJP. SK $\mathrm{Sa}_{\mathrm{Ca}}$ channels are not a likely candidate either, because apamin did not attenuated the SNP-induced hyperpolarisation in this tissue. We concluded that NO activates $\mathrm{K}_{\mathrm{ATP}}$ channels to produce the slow IJP via cGMP but not via PKG, though it needs further investigation to elucidate the responsible channel(s) for the nitrergic fast IJP. Selemidis et al. also suggested that in the rat anococcygeus smooth muscle, NO produced NANC IJP via activation of cGMP-dependent channels, which are insensitive to apamin, iberiotoxin, charybdotoxin and glibenclamide (Selemidis et al., 1998). 

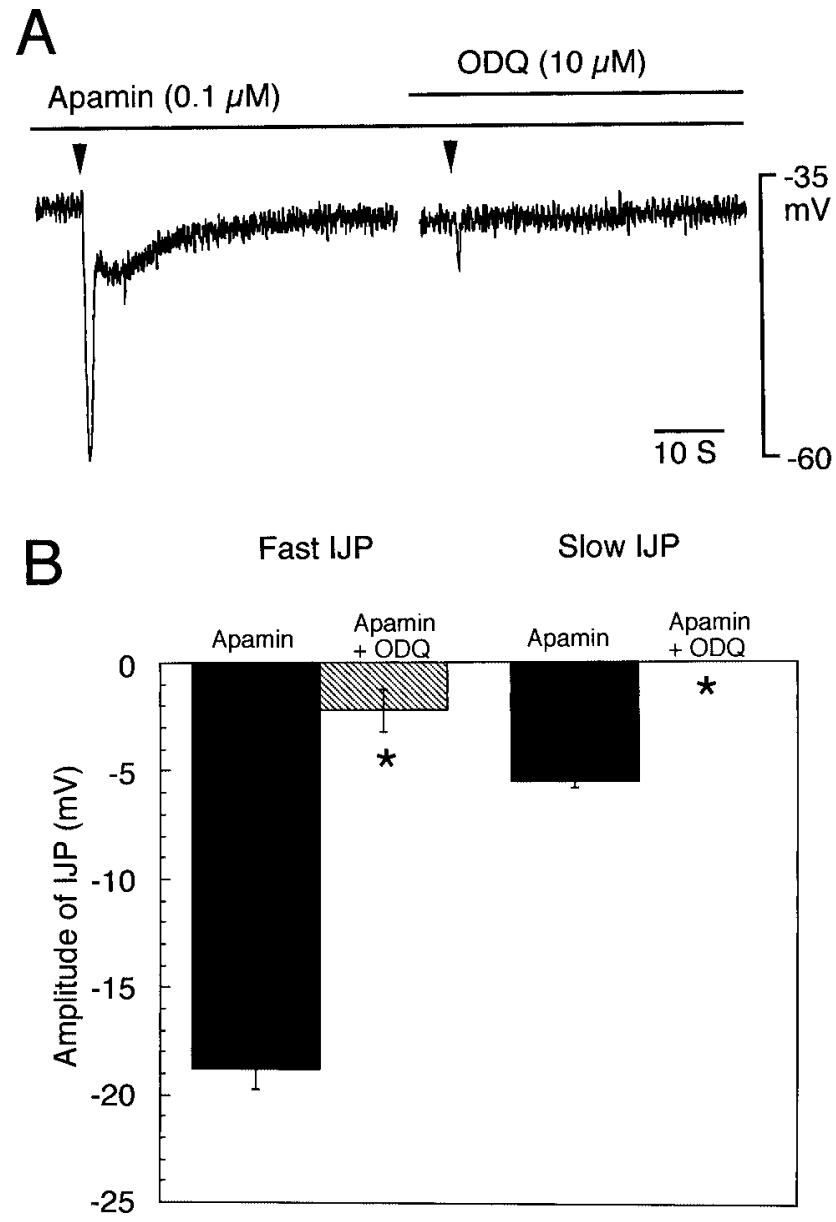

Fig. 9. Effect of ODQ on the apamin-insensitive IJP. A: Representative traces showing the effect of ODQ $(10 \mu \mathrm{M})$ on IJP. IJP was evoked by EFS $(10$ pulses in $20 \mathrm{~Hz}, 30 \mathrm{~V}$ intensity) in the presence of atropine $(1 \mu \mathrm{M})$, nifedipine $(1 \mu \mathrm{M})$ and apamin $(0.1 \mu \mathrm{M})$. The membrane potential was $-37 \mathrm{mV}$. EFS was applied at the time indicated by an arrow head. B: Each column indicates amplitude of the fast and slow IJP in the absence and presence of ODQ $(10 \mu \mathrm{M})$. Values are mean \pm S.E.M. $(\mathrm{n}=4)$. ${ }^{\star} P<0.05$ vs. apamin.

\section{Purinergic fast IJP}

ATP has been reported as a neurotransmitter for the fast IJP in the several parts of gastrointestinal tract, for example guinea-pig ileum (Crist et al., 1992), guinea-pig internal anal sphincter (Rae and Muir, 1996), guinea-pig LOS (Imaeda et al., 1998) and human jejunum (Xue et al., 1999). In the present study, PPADS, an inhibitor of $\mathrm{P}_{2}$ purinoceptor (Lambrecht $e t$ al., 1992), inhibits about one third of the fast IJP, but did not attenuate the slow IJP (Fig. 6). This result suggests that ATP mediates a part of the fast IJP via $\mathrm{P}_{2}$ purinoceptor. Guanethidine, a blocker of adrenergic nerve transmission, inhibited the fast IJP similarly to PPADS (Fig. 5). Guanethidine also inhibited the slow IJP, but it was not statistically significant. Although further 
investigation is needed to elucidate the origin of ATP, it is speculated that ATP is released from adrenergic nerves. In the guinea-pig LOS, it has been reported that ATP released from adrenergic nerve evokes IJP (Imaeda et al., 1998), supporting our hypothesis. In Fig. 5, in the presence of both atropine and guanethidine, an IJP with fast and slow components has been observed. This is the very NANC IJP in the murine LOS.

Apamin is an inhibitor of $\mathrm{SK}_{\mathrm{Ca}}$ channels, and the activation of apamin-sensitive $\mathrm{Ca}^{2+}$-activated $\mathrm{K}^{+}$channels $\left(\mathrm{K}_{\mathrm{Ca}}\right)$ by ATP has been reported in murine colonic smooth muscle (Koh et al., 1997) and guinea-pig LOS (Imaeda et al., 1998). So, we investigated the effect of apamin on IJP. Apamin did not change the slow IJP, but partially attenuated the fast IJP. After treatment of apamin, the residual IJP was almost abolished by ODQ (Fig. 9). ODQ inhibited the nitrergic fast IJP and abolished the nitrergic slow IJP and greatly inhibited the SNP-induced hyperpolarisation (Figs. 3 and 4). These observations suggest that apamin is sensitive to nonnitrergic IJP, that is to say purinergic IJP. Taken together, these results indicate the likelihood that ATP released from adrenergic nerve activates apamin-sensitive $\mathrm{K}_{\mathrm{Ca}}$ channels, resulting in the production of hyperpolarisation.

In summary, in smooth muscle of the murine LOS, IJP evoked by EFS consist of three parts, namely a fast purinergic IJP, a fast nitrergic IJP and a slow nitrergic IJP. The purinergic IJP was produced by the activation of apamin-sensitive $\mathrm{K}_{\mathrm{Ca}}$ channels. The slow nitrergic IJP was produced by the activation of $\mathrm{K}_{\mathrm{ATP}}$ channels via cGMP. The fast nitrergic IJP was also produced via cGMP, not $\mathrm{PKG}$, and responsible channels remained uncertain.

\section{Acknowledgements}

This project was supported by a research grant from the Wellcom Trust of UK and the Uehara Memorial Medical Research Foundation of Japan.

\section{References}

Allescher, H.D., Berezin, I., Jury, J. and Daniel, E.E. (1988). Characteristics of canine lower esophageal sphincter: a new electrophysiological tool. Am. J. Physiol. 255: G441-G453.

Bolton, T.B. and Large, W.A. (1986). Are junction potentials essential? Dual mechanism of smooth muscle cell activation by transmitter released from autonomic nerves. Q. J. Exp. Physiol. 71: 1-28.

Conklin, J.L., Du, C., Murray, J.A. and Bates, J.N. (1993). Characterization and mediation of inhibitory junction potentials from opossum lower esophageal sphincter. Gastroenterol. 104: 1439-1444.

Cornfield, D.N., Reeve, H.L., Tolarova, S., Weir, E.K. and Archer, S. (1996). Oxygen causes fetal pulmonary vasodilation through activation of a calcium-dependent potassium channel. Proc. Natl. Acad. Sci. USA 93: 8089-8094.

Crist, J.R., He, X.D. and Goyal, R.K. (1992). Both ATP and the peptide VIP are inhibitory neurotransmitters in guinea-pig ileum circular muscle. J. Physiol. (Lond.) 447: 119-131.

Daniel, E.E., Jager, L.P. and Jury, J. (1989). Vasoactive intestinal polypeptide and non-adrenergic, noncholinergic inhibition in lower oesophageal sphincter of opossum. Br. J. Pharmacol. 96: 746-752.

De Man, J.G., Pelckmans, P.A., Boeckxstaens, G.E., Bult, H., Oosterbosch, L., Herman, A.G. and Van Maercke, Y.M. (1991). The role of nitric oxide in inhibitory non-adrenergic non-cholinergic neurotransmission in the canine lower oesophageal sphincter. Br. J. Pharmacol. 103: 1092-1096. 
Garthwaite, J., Southam, E., Boulton, C.L., Nielsen, E.B., Schmidt, K. and Mayer, B. (1995). Potent and selective inhibition of nitric oxide-sensitive guanylyl cyclase by $1 \mathrm{H}-[1,2,4]$ oxadiazolo $[4,3-$ a]quinoxalin-1-one. Mol. Pharmacol. 48: 184-188.

Goyal, R.K. and He, H.E. (1998). Evidence for NO ${ }^{*}$ redox form of nitric oxide as nitrergic inhibitory neurotransmitter in gut. Am. J. Physiol. 275: G1185-G1192.

Goyal, R.K. and Paterson, W.G. (1989). Esophageal motility. In: Handbook of Physiology, The Gastrointestinal System, ed. by J.D. Wood, Waverly Press, Bethesda, Vol 1, pp. 865-908.

Hoyle, C.H.V. and Burnstock, G. (1989). Neuromuscular transmission in the gastrointestinal tract. In: Handbook of Physiology, The Gastrointestinal System, ed. by J.D. Wood, Waverly Press, Bethesda, Vol 1, pp. 435-464.

Imaeda, K., Joh, T., Yamamoto, Y., Itoh, M. and Suzuki, H. (1998). Properties of inhibitory junctional transmission in smooth muscle of the guinea pig lower esophageal sphincter. Jpn. J. Physiol. 48: 457-465.

Kase, H., Iwahashi, K., Nakanishi, S., Matsuda, Y., Yamada, K., Takahashi, M., Murakata, C., Sato, A. and Kaneko, M. (1987). K-252 compounds, novel and potent inhibitors of protein kinase C and cyclic nucleotide-dependent protein kinases. Biochem. Biophys. Res. Commun. 142: 436-440.

Kim, C.D., Goyal, R.K. and Mashimo, H. (1999). Neuronal NOS provides nitrergic inhibitory neurotransmitter in mouse lower esophageal sphincter. Am. J. Physiol. 277: G280-G284.

Koh, S.D., Dick, G.M. and Sanders, K.M. (1997). Small-conductance $\mathrm{Ca}^{2+}$-dependent $\mathrm{K}^{+}$channels activated by ATP in murine colonic smooth muscle. Am. J. Physiol. 273: C2010-C2021.

Lambrecht, G., Friebe, T., Grimm, U., Windscheif, U., Bungardt, E., Hildebrandt, C., Baumert, H.G., Spatz-Kumbel, G. and Mutschler, E. (1992). PPADS, a novel functionally selective antagonist of $\mathrm{P}_{2}$ purinoceptor-mediated responses. Eur. J. Pharmacol. 217: 217-219.

Moncada, S., Palmer, R.M. and Higgs, E.A. (1991). Nitric oxide: physiology, pathophysiology, and pharmacology. Pharmacol. Rev. 43: 109-142.

Murphy, M.E. and Brayden, J.E. (1995). Nitric oxide hyperpolarizes rabbit mesenteric arteries via ATPsensitive potassium channels. J. Physiol. (Lond.) 486: 47-58.

Ny, L., Alm, P., Larsson, B., Ekstrom, P. and Andersson, K.E. (1995). Nitric oxide pathway in cat esophagus: localization of nitric oxide synthase and functional effects. Am. J. Physiol. 268: G59G70.

Porter, V.A., Bonev, A.D., Knot, H.J., Heppner, T.J., Stevenson, A.S., Kleppisch, T., Lederer, W.J. and Nelson, M.T. (1998). Frequency modulation of $\mathrm{Ca}^{2+}$ sparks is involved in regulation of arterial diameter by cyclic nucleotides. Am. J. Physiol. 274: C1346-C1355.

Rae, M.G. and Muir, T.C. (1996). Neuronal mediators of inhibitory junction potentials and relaxation in the guinea-pig internal anal sphincter. J. Physiol. (Lond.) 493: 517-527.

Robertson, B.E., Schubert, R., Hescheler, J. and Nelson, M.T. (1993). cGMP-dependent protein kinase activates Ca-activated $\mathrm{K}$ channels in cerebral artery smooth muscle cells. Am. J. Physiol. 265: C299-C303.

Selemidis, S., Ziogas, J. and Cocks, T.M. (1998). Apamin- and nitric oxide-sensitive biphasic nonadrenergic non-cholinergic inhibitory junction potentials in the rat anococcygeus muscle. $J$. Physiol. (Lond.) 513: 835-844.

Ward, S.M., Morris, G., Reese, L., Wang, X.Y. and Sanders, K.M. (1998). Interstitial cells of Cajal mediate enteric inhibitory neurotransmission in the lower esophageal and pyloric sphincters. Gastroenterol. 115: 314-329.

Xue, L., Farrugia, G., Sarr, M.G. and Szurszewski, J.H. (1999). ATP is a mediator of the fast inhibitory junction potential in human jejunal circular smooth muscle. Am. J. Physiol. 276: G1373-G1379.

Yuan, S., Costa, M. and Brookes, S.J. (1998). Neuronal pathways and transmission to the lower esophageal sphincter of the guinea Pig. Gastroenterol. 115: 661-671.

(Received August 1, 2003; Accepted August 30, 2003) 